\title{
PENGELOLAAN HASIL PERTANIAN DALAM MENINGKATKAN HARGA JUAL PADA PETANI DI DESA CICALENGKA KECAMATAN PAGEDANGAN KABUPATEN TANGERANG - BANTEN
}

\author{
Iriana Kusuma Dewi, Ahyani, Aden Prawiro Sudarso, Liawati, Widowati \\ Universitas Pamulang \\ Email: dosen01729@unpam.ac.id
}

\begin{abstract}
The purpose of community service activities is to carry out one of tri darma universities, especially at Pamulang University. In addition, it is hoped that with community service the existence of universities can contribute to the development of scientific application to the community. The method used in this community service verbally abuses the material in the implementation of this material in counseling containing about how to create a website and market agricultural produce. So that the community (farmers) can also manage their own sales of agricultural produce. The result of community service obtained is an activity carried out for the people of Cicalengka Village is an activity to overcome problems in selling and marketing agricultural products. Where the activities are given is how to create a website to sell agricultural produce online so that farmers can determine their own selling price as well as the packaging model for packing the agricultural products. The knowledge gained on community service is expected to provide more insight into how to sell and market agricultural produce using the website, this aims to make farmers profit according to what they have spent on production costs, especially for farmers in Cicalengka Village, Kec. Pagedangan Kab. Tangerang - Banten.
\end{abstract}

Keywords : Increase In Production, Agriculture, Entrepreneurship

\begin{abstract}
Abstrak
Tujuan dari Kegiatan Pengabdian Kepada Masyarakat adalah untuk melaksanakan salah satu Tri Dharma Perguruan Tinggi khususnya di Universitas Pamulang. Selain itu diharapkan dengan pengabdian kepada masyarakat tersebut keberadaan perguruan tinggi dapat memberikan kontribusi kepada pengembangan penerapan keilmuan kepada masyarakat. Metode yang digunakan pada pengabdian kepada masyarakat ini penyampaikan materi secara verbal dalam pelaksanaan ini materi dalam penyuluhan berisi tentang bagaimana cara untuk membuat website dan memasarkan hasil produksi pertanian. Sehingga masyarakat (petani) juga bisa mengelola sendiri penjualan hasil produksi pertanian. Hasil pengabdian masyarakat yang diperoleh adalah kegiatan yang dilaksanakan untuk
\end{abstract}


masyarakat Desa Cicalengka adalah kegiatan untuk mengatasi permasalahan dalam menjual serta memasarkan hasil produksi pertanian. Dimana kegiatan yang diberikan adalah bagaimana cara membuat website untuk menjual hasil produksi pertanian secara online sehingga petani dapat menentukan sendiri harga jualnya serta model kemasan untuk packing hasil pertanian tersebut. Ilmu yang diperoleh pada pengabdian masyarakat ini harapannya semakin memberikan wawasan mengenai bagaimana cara menjual serta memasarkan hasil produksi pertanian dengan menggunakan website, hal ini bertujuan agar para petani dapat memperoleh keuntungan sesuai dengan apa yang sudah mereka keluarkan untuk biaya produksi khususnya bagi para petani di Desa Cicalengka, Kec. Pagedangan Kab. Tangerang - Banten.

Kata Kunci : Peningkatan Hasil Produksi, Pertanian, Wirausaha

\section{A. PENDAHULUAN}

Pertanian adalah kegiatan pemanfaatan sumber daya hayati yang dilakukan manusia untuk menghasilkan bahan pangan, bahan baku industri, atau sumber energi, serta untuk mengelola lingkungan hidupnya. Kegiatan pemanfaatan sumber daya hayati yang termasuk dalam pertanian biasa dipahami orang sebagai budidaya tanaman atau bercocok tanam. Tanaman pangan merupakan salah satu contoh pertanian yang banyak dipilih di Indonesia seperti padi, umbi-umbian, jagung dan lain-lain.

Dalam usaha agribisnis, pemasaran menjadi kunci utama agar produk pertanian bisa sampai ke pasar atau konsumen akhir. Pada kegiatan pemasaran, seringkali dijumpai rantai pemasaran yang panjang sehingga banyak pelaku pemasaran yang terlibat di dalamnya. Hal inilah yang menyebabkan tingginya akumulasi keuntungan yang diambil dari setiap pelaku pemasaran. Harga yang diterima petani sebagai produsen dan yang dibayarkan oleh konsumen akhir akan berbeda signifikan.

\section{Rumusan Masalah}

Berdasarkan latar belakang masalah di atas, maka fokus pengabdian masyarakat dibatasi pada ruang lingkup penjualan hasil produksi pertanian. Adapun kegiatannya adalah dengan memberikan edukasi secara visual dan verbal kepada masyarakat khususnya para petani bahwa proses penjualan dan pemasaran dapat dilakukan dengan sistem online dengan cara membuat website.

2. Tujuan Pelaksanaan

a. Memberikan edukasi dan meningkatkan ketrampilan mengenai penjualan hasil produksi pertanian secara online,

b. Membantu petani agar lebih baik lagi dalam hal pengemasan hasil produksi pertanian yang akan dijual,

c. Membantu petani agar memperoleh pendapatan lebih besar dari sebelumnya. 


\section{B. METODE PELAKSANAAN}

Metode pelaksanaan kegiatan ini dilakukan dalam 3 (tiga) rangkaian tahapan, yaitu; Pertama tahapan Pendahuluan, Kedua tahapan Sosialisasi dan Ketiga adalah tahapan Pelaksanaan. Tahapan pendahuluan meliputi kegiatan survei lapangan dan hubungan dengan objek lokasi pengabdian serta penyusunan rancangan kegiatan dan keluaran dari kegiatan tersebut.

Tahapan Sosialisasi; dalam tahapan ini tim yang sudah menyusun dan membentuk rancangan acara kemudian menyampaikan kepada pihak Kepala Desa Cicalengka, Tangerang - Banten serta pelaksanaan beserta keluaran yang ditentukan. Dan terakhir adalah Tahapan pelaksanaan; tahapan ini merupakan pelaksanaan dari rancangan kegiatan yang telah ditetapkan.

\section{HASIL DAN PEMBAHASAN}

Pengabdian Kepada Masyarakat (PKM) yang merupakan salah satu Tridharma Perguruan Tinggi adalah sesuatu yang wajib dilakukan oleh setiap Dosen tidak terkecual Dosen dari Universitas Pamulang.

Melalui LPPM (Lembaga Penelitian dan Pengabdian Masyarakat) Universitas Pamulang telah dan akan terus melaksanakan kegiatan Tridharma Perguruan Tinggi termasuk kegiatan penyuluhan pengelolaan hasil pertanian pada Desa Cicalengkan yang merupakan bagian dari Pengabdian Kepada Masyarakat (PKM).

Dengan adanya kegiatan ini, diharapkan adanya sumbangsih baik itu dalam segi pemikiran, wawasan serta implementasi keilmuan yang dipelajari di Perguruan Tinggi bisa dibawah ke ranah praktis kehidupan.

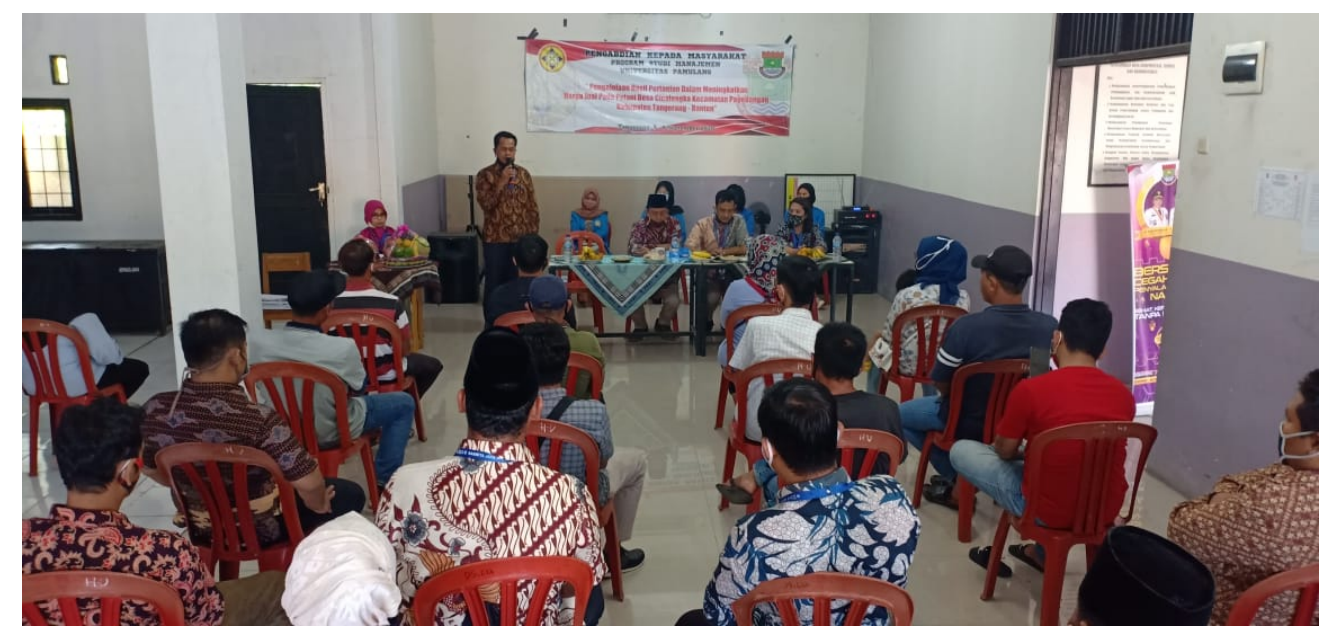

Gambar 1. Penyampaian Materi 


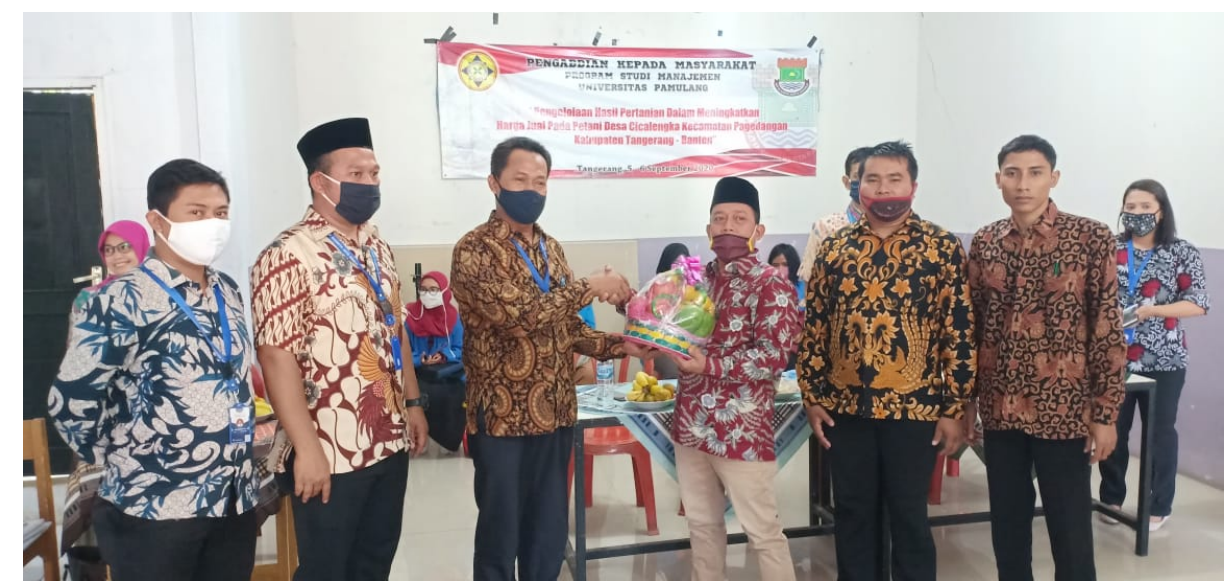

Gambar 2. Penyerahan Bingkisan

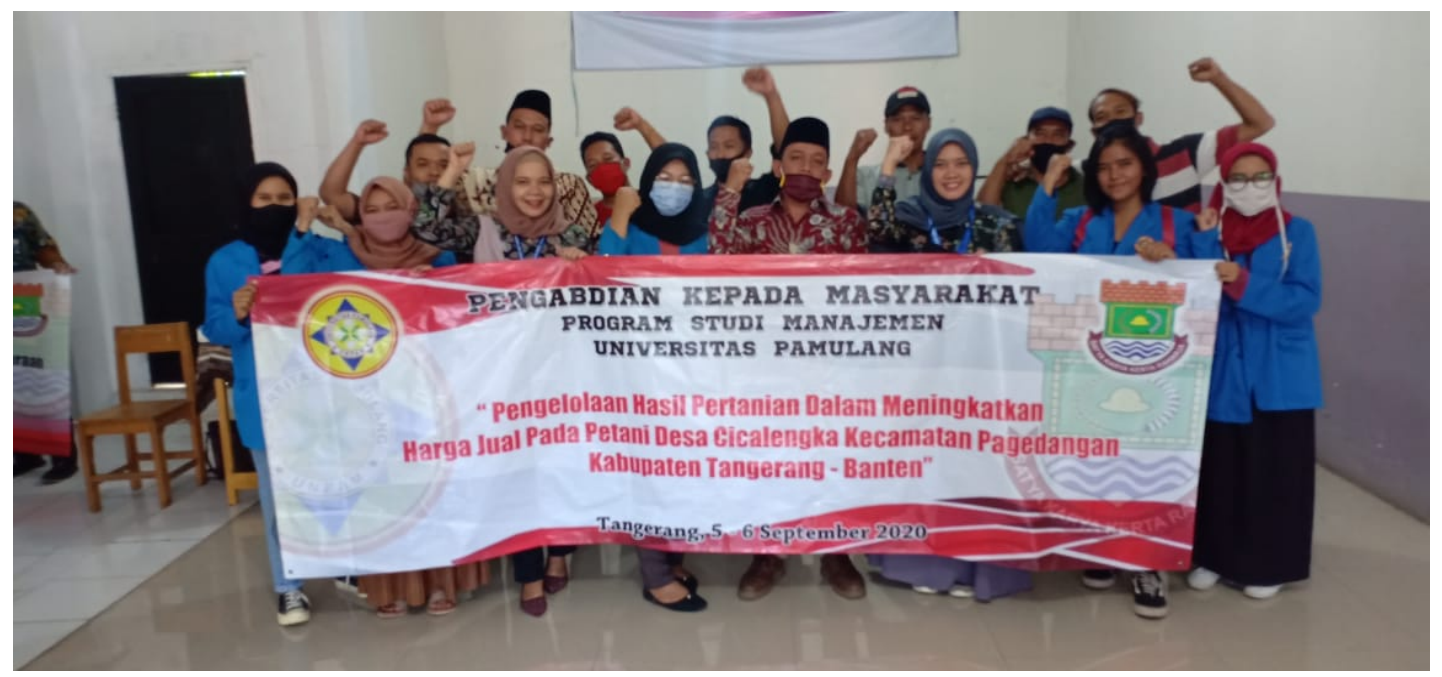

Gambar 3. Foto Bersama

\section{KESIMPULAN DAN SARAN}

\section{Kesimpulan}

PKM dengan judul pengelolaan hasil pertanian dalam meningkatkan harga jual merupakan PKM yang bertujuan untuk memperkenalkan dan memberikan pengetahuan serta pemahaman kepada masyarakat Desa Cicalengka, Kec. Pagedangan Kab. Tangerang Banten mengenai bagaimana cara menjual hasil produksi secara online dan bagaimana cara mengemas produk agar lebih menarik, dan juga merupakan wahana bagi dosen untuk mengabdikan keilmuannya.

\section{Saran}

Pelaksanaan kegiatan PKM ini diharapkan dapat berkembang lebih luas lagi khususnya dalam bidang pemasaran sehingga metode penjualan secara online dapat lebih dikenal secara luas bagi masyarakat serta bagaimana caranya untuk menarik pembeli melalui pengemasan yang lebih menarik. 


\section{DAFTAR PUSTAKA}

Dewi, I. K., dan Solihin, D. (2020). Pengaruh Current Ratio Dan Net Profit Margin Terhadap Harga Saham Pada Perusahaan Makanan Dan Minuman Yang Terdaftar Di Bursa Efek Indonesia (BEI) Periode 2015-2018. JURNAL ILMIAH FEASIBLE: Bisnis, Kewirausahaan \& Koperasi. Vol. 2, No. 2.

Dewi, I.K., Rahman, A. S., Harturi, E. T. K., Septiani, Y., \& Jamaludin, P.P. (2020). Penyuluhan Pemanfaatan Limbah Buah Menjadi Pupuk Cair Organik Untuk Memenuhi Kebutuhan Petani Buah Palawija Dan Sayuran Di Desa Karang Dadap Kecamatan Kalibagor, Banyumas - Jawa Tengah. Indonesian Journal of Society Engagement. Vol. 1. No. 1.

Ilham dan Hermanto. (2007). Dampak Kebijakan Harga Pangan dan Kebijakan Moneter Terhadap Stabilitas Ekonomi Makro. Jurnal Agro Ekonomi. 25 (1) 55 - 83.

Isa, I. (2006). Strategi Pengendalian Alih Fungsi Lahan Pertanian. http://balittanah litbang.deptan.go.id/dokumentasi/prosiding/mflp2006/.

Masrukin S.P, (2020). Pemberdayaan Penyuluhan Pertanian Dalam Menerapkan-Inovasi Teknologi Pertanian Terkini dan Dunia Maya Menyongsong Era Digital, Globalisasi dan Pandemi Global Covid -19. Nganjuk.

Nugroho I., \& Dahuri R. (2004). Pembangunan Wilayah: Persepsi Ekonomi, Sosial dan Lingkungan. Jakarta, LP3ES.

Pesandaran, E, (2006). Alternatif Kebijakan Pengendalian Konversi Lahan Sawah-Beririgasi di Indonesia. Jurnal Litbang Pertanian. 25(4):123-129.

Solihin, D. (2019), Pengaruh Current Ratio dan Debt To Equity Ratio Terhadap Return On Asset (ROA) Pada PT Kalbe Farma, Tbk. KREATIF: Jurnal Ilmiah Prodi Manajemen Universitas Pamulang 7 (1), 115-122.

Solihin, D. (2020), Faktor-Faktor Yang Mempengaruhi Kinerja Pemasaran Pada PT Prima Ufuk Semesta (Studi Empiris Pada Outlet Rekanan PT. Prima Ufuk Semesta di Wilayah JABODETABEK), Jurnal Semarak, Vol. 3. No. 1.

Solihin, D. (2020), Pengaruh Kepercayaan Pelanggan Dan Promosi Terhadap Keputusan Pembelian Konsumen Pada Online Shop Mikaylaku Dengan Minat Beli Sebagai Variabel Intervening. Jurnal Mandiri. Vol. 4. No. 1.

Solihin, D., dan Wibawanto, E. (2020). Pengaruh Kualitas Pelayanan, Harga, Dan Promosi Terhadap Keputusan Pelanggan Dalam Memilih Klub Basket Satria Indonesia Tangerang Selatan. Jurnal Pemasaran Kompetitif. Vol. 3. No. 3.

Sulaeman, (2018). Pkm Kelompok Tani Sayuran Dalam Penggunaan Teknologi -Pengelolaan Hama dan Penyakit Ramah Lingkungan dan Teknologi-Pemupukan Organik Untuk Meningkatkan Produktivitas dan -Pendapatan Petani Di Desa Karawana Kecamatan Dolo Kabupaten - Sigi. Jurnal Abditani. 1 (1) 50 - 57.

Yunita I, (2007). Lahan Pertanian Abadi (LPA) di Kabupaten Tangerang. Jurnal-Litbang Pertanian. Bekasi. 